\title{
SPLENOMEGALY AND HEPATOMEGALY IN AN ADOLESCENT SIMULATING BANTI'S SYNDROME
}

BY

\author{
A. F. MacCABE, M.B.Ch.B., D.P.H., Capt., R.A.M.C. \\ Pathologist to a Military Hospital
}

AND

W. G. TAAFFE, M.B.Ch.B., Capt., R.A.M.C.

Banti's disease, or Banti's syndrome as it is now generally called, is really a symptom complex, characterized by splenomegaly, and a progressive anaemia, with a tendency to gastro-oesophageal haemorrhage, and often accompanied by some degree of hepatic involvement.

In Banti's description of the condition, he distinguished three stages:-

(1) Splenomegaly with an associated secondary anaemia.

(2) A short transitional stage with hepatic enlargement and jaundice.

(3) A terminal stage characterized by cirrhosis of the liver and ascites.

The case described exhibited many of the above phenomena.

\section{Clinical record}

The patient, a boy of fourteen years of age, was admitted to hospital on September 16, 1944, with a history of increasing jaundice since May 1944, but he had apparently had attacks during the previous twelve months of a less severe nature. Increasing general debility and anorexia had been noticed for two years.

Previous history. He was apparently quite healthy until September, 1942, but since then had only been able to attend school spasmodically. Transient attacks of jaundice during the past two years were noted by his family, each attack lasting perhaps for 48 hours. This jaundice has persisted steadily since May 1944, accompanied by increasing lassitude, anorexia and debility. There was no history of intestinal infection, or of jaundice in any of his school-fellows. The onset was insidious, there never had been any pain. Tonsillectomy was performed in November 1943.

Family history. Father is a healthy robust man. Mother died from pulmonary tuberculosis when the patient was five years of age. There is a history of lung and bone tuberculosis on both sides of the family.

Clinical examination. T. $102^{\circ}$ F. P. 104. R. 22. There was a definite icterus present in all areas of a deep lemon tinge, with an obvious anaemia. He was lacking in energy, and was too tired to speak. There was complete loss of appetite.
NoSE AND PHARYNX. Healthy.

CHEST. Normal.

Circulatory system. Pulse regular in time and force and of poor volume. Heart sounds clear and pure in all areas. Pitting oedema of lower limbs and sacral region.

ABDOMEN. Doughy and distended, gaseous, free fluid.

Liver. Palpable, 2 fingers below costal margin, not tender.

SpleEN. Palpable to level of umbilicus. Smooth, not tender.

KIDNEYS. Normal.

ReCTAL eXAMination. Normal. There was no evidence of venous obstruction in the abdomen.

X-RAY OF ABDOMEN. The outline of the spleen was well seen, being contrasted medially against the gas bubble of the stomach and inferiorly against the splenic flexure which was distended with gas. It showed marked enlargement, and displaced the stomach to the right and the splenic flexure downwards.

The anterior margin of the liver was well seen and showed a general enlargement, displacing the gas-filled hepatic flexure downwards. The right dome of the diaphragm was not displaced. No calcified mesenteric glands were seen.

X-RAY OF CHEST. Heart and lungs appeared normal. Unfortunately a barium swallow to demonstrate any oesophageal varices that may have been present, was prevented by the patient's poor general condition.

Blood investigation.

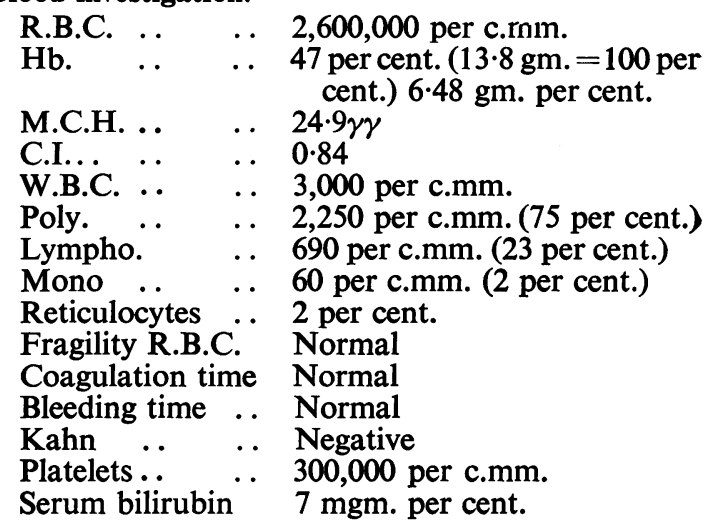


Urine. No albumin or sugar. No excess urobilin.

Faeces. No abnormality.

The red blood cells were poorly filled and showed marked anisocytosis without macrocytosis. There was a moderate degree of stippling, but there were no haemoglobinized megaloblasts or erythroblasts, or primitive white cells. The patient's condition deteriorated generally, jaundice increasing to a marked degree. Large quantities of flatus were passed per rectum. Severe repeated epistaxis occurred. The appetite was poor with increasing general lassitude and weakness. His condition deteriorated so rapidly, that a blood transfusion was given (one pint) with the hope of rendering him fit for transfer, with a view to his having some form of specific treatment; this resulted in a temporary improvement in his general condition, but unfortunately a haematemesis occurred and he died on September 29, 1944. Time and facilities did not permit of a more complete investigation.

Post-mortem examination. General nutrition was fair. There was a marked generalized jaundice of a deep yellow colour, with gross oedema of the lower limbs and sacral regions. There were no subcutaneous or intramuscular haemorrhages. The abdomen contained a large quantity of straw coloured free liquid.

Spleen (wt. 1,380 gm.) was grossly enlarged, but of normal contour. The capsule was slightly thickened and was adherent to the diaphragm. The cut surface was deep brick red in colour with very prominent Malpighian bodies. There was no thrombosis seen in the splenic vein.

Microscopic APPEARANCES. The capsule was a little thickened. The venous sinuses were promiment, dilated and congested, many containing desquamated endothelial cells, large mononuclears and lymphocytes. A few of the veins showed thickening of the walls. The Malpighian bodies were fairly distinct. The central arteries showed a moderate degree of hyalinization, the lumen being practically obliterated in several. In some areas fibrous tissue proliferation extended from the arterioles into the Malpighian bodies with a few peri-arterial haemorrhages. There were scattered areas of fibrosis.

Liver. (wt. 2,350 gm.) was enlarged. Capsule not thickened. It was of a greyish-bluff colour, soft and friable with a few firm nodular areas. The cut surface presented a fine granularity more marked in the upper left zone and was slate-grey in colour with bright petechiae present.

MicROSCOPIC APPEARANCES. The lobules were indistinct. Fibrosis was present throughout, more marked in the vicinity of Glisson's capsule, which showed round cell infiltration. There were large areas of haemorrhage, degeneration and necrosis. Both spleen and liver gave a positive prussian-blue reaction. The lower end of the oesophagus had dilated varices, the stomach contained a large quantity of blood from an apparent recent haemorrhage. The mucous membrane did not show any changes. There was no evidence of tuberculosis in the mesenteric glands or lungs, and heart and adrenals appeared normal.

\section{Discussion}

Splenomegaly and hepatomegaly with anaemia, offer many possibilities in differential diagnosis. The case exhibited many interesting phenomena, one or more of which may be met with in many other conditions with a similar history.

It was, therefore, by excluding these other possibilities, that this case was regarded as one of Banti's syndrome. Hodgkin's disease was eliminated by the excessive splenomegaly, absence of glandular involvement, and the absence of typical Hodgkin's tissue in spleen and liver. In acholuric jaundice there is an increased fragility of the erythrocytes and a high recticulocyte count and often a family history. Cirrhosis of the liver with splenomegaly was also considered. The spleen was thought to be too large for Gaucher's disease and there were no Gaucher cells in spleen or liver.

Although it is maintained by some that true pernicious anaemia does not occur in children, it was, nevertheless, considered. The blood picture, however, was not typical of pernicious anaemia, there being no macrocytosis, haemoglobinized megaloblasts, erythroblasts, nor was there a 'right shift' in the Arneth count. Epistaxis and internal haemorrhage are rare in pernicious anaemia.

The leukaemias were excluded by blood picture. However, aleukaemic leukaemia had to be seriously considered, but the absence of the primitive white cells in the blood discredited this possibility. The findings were not typical of essential thrombocytopenic purpura. There were no signs of tuberculosis in spleen or other organs. There was no tumour present.

Felty's syndrome of chronic arthritis and splenomegaly, was not seriously considered as in the series reported the age incidence was about fifty years. In Lederer's anaemia, the liver and spleen are not usually so large and there is generally a leucocytosis with a few myelocytes and metamyelocytes. Von Jaksch's anaemia is generally found at six weeks to three years and a leucocytosis with primitive leucocytes is generally present.

There are apparently various opinions as to the etiology and findings in Banti's syndrome and as to whether the condition is primarily one of splenic or liver involvement.

Ravenna (1940) considers that the splenic changes are probably due to primary lesions of the splenic artery, the regulating power of which becomes insufficient to control the inflow of blood, and that the consequent congestive splenomegaly is the cause of the circulatory disturbance in the portal bed. Secondarily, hepatic cirrhosis and venous thrombosis may aggravate the state of portal circulation. McMichael (1934) maintains that the disease is primarily a hepatic or portal disorder, and that the average weight of the spleen is $876 \mathrm{gm}$. Poynton, Thursfield, and Paterson (1922) state that the disease can begin before puberty. Smith and Faber (1935) describe cases which did not progress to hepatic cirrhosis and ascites. Martin (1936) states that the disease is rare before puberty. 
The case described appears as if it may have passed through three stages similar to those described by Banti (1910) :-

(1) Enlarged spleen with anaemia,

(2) Transition stage with enlargement of liver and jaundice,

(3) Terminal stage of cirrhosis of liver, ascites, increasing jaundice, cachexia and death.

\section{Summary}

(1) A case of splenomegaly and hepatomegaly with severe anaemia in an adolescent, exhibiting the Banti's syndrome, is described.

(2) The differential diagnosis is considered.
(3) Views expressed in recent literature are outlined.

Thanks are due to Mr. I. McClure, F.R.C.S.Ed. for permission to publish the case, and Major R. L. Mansi, R.A.M.C. for x-ray examination.

\section{REFERENCES}

Banti, G. (1910). Folia Haemat. Lpz., 10, 33.

McMichael, J. (1934). J. Path. Bact., 39, 481.

Martin, L. C. (1936). Arch. Dis. Childh., 11, 233.

Poynton, F. J., Thursfield, H., and Paterson, D. (1922) Brit. J. Child. Dis., 19, 57.

Ravenna, P. (1940). Arch. intern. Med., 66, 879.

Smith, R. M., and Faber, S. (1935). J., Pediat., 7, 565.

Whitby, L.E. H., and Britton, C. J. C. (1942). Disorders of the blood, Lond., 4th. ed. 